\title{
ПОДХОДЫ К РОЛИ СОЦИАЛЬНОЙ ЗАЩИТЫ НАСЕЛЕНИЯ В ЖИИНИ ОБЩЕСТВА И СОВРЕМЕННЫЕ ВЫЗОВЫ, СТОЯЩИЕ ПЕРЕД НЕЙ
}

\begin{abstract}
АНнОтАЦИЯ. В условиях ограниченности природных ресурсов, изменении климата на планете и ухудшении общей экономической ситуации остро встает вопрос о роли и структуре социальной защиты как системе управления социальными рисками населения страны. Важную роль в осмыслении потребности и масштабе присутствия социальной зашиты играют международные организации, такие как Международная организация труда, Международная ассоциация социального обеспечения. Особенно остро сегодня встает вопрос о поиске финансовых резервов для поддержания достигнутого уровня материальной защиты за счет системы социального обеспечения в условиях ограниченности природных ресурсов, ухудшении климата, изменения социальных и экономических условий в мире.

кЛючЕВЫЕ СЛОВА. Социальная защита; структура социальной защиты; Международная организация труда; минимальный уровень социальной защиты.

ИНФОРМАЦИЯ О СТАТЬЕ. Дата поступления 29 марта 2017 г.; дата принятия к печати 17 апреля 2017 г.; дата онлайн-размещения 23 июня 2017 г.
\end{abstract}

E. V. Ageeva

Baikal State University,

Irkutsk, Russian Federation

\section{APPROACHES TO ROLE OF SOCIAL PROTECTION FOR THE PUBLIC IN SOCIETY'S LIFE AND MODERN CHALLENGES FACING IT}

\begin{abstract}
In terms of natural resource limitation, change of the climate on the planet and deterioration of the general economic situation, there arises an issue of the role and structure of the social protection as a system of social risk management for the country's population. An important role in comprehension of the requirement and the scale of the social protection availability is played by the international organizations, such as International Labor Organization (ILO), International Association of Social Security (IASS). Of topical issue today is search for financial reserves for maintaining the attained level of material protection at the expense of the social welfare system in terms of natural resource limitation, determination of the climate, changes of the social and economic factors.

KEYWORDS. Social protection; structure of social protection; International Labor Organization; minimum level of social protection.

ARTICLE INFO. Received March 29, 2017; accepted April 17, 2017; available online June 23, 2017.
\end{abstract}

Рассматривая сущность социальной защиты населения с социально-экономической точки зрения, в первую очередь рассматривается ее роль в обеспечении защиты материального и социального положения жителей страны от неблагоприятного воздействия социальных рисков. В ее основе лежат отношения по реализации закрепленных законом страны социальных гарантий и прав человека, направленных на обеспечение нормальных условий жизнедеятельности и компенсацию последствий социальных рисков [1]. Конкретное содержание системы социальной защиты во многом определяется многими факторами общественно-

\section{Baikal Research Journal}


го развития. Если наличие социальных рисков, угрожающих жизнедеятельности человека, обусловливает саму необходимость определенной защиты от их действия, то организация, объем и инструменты осуществления этой защиты определяются уже конкретными экономическими, политическими и демографическими характеристиками современного этапа развития общества [2, с. 150]. Демографическая ситуация характеризует основные параметры человеческого общества, определяя сам объект защиты. Экономические факторы определяют материальную базу всего социального комплекса, диктуют условия формирования трудовых ресурсов, обеспечивают уровень индивидуального и общественного благосостояния, закладывают основы социальной стратификации населения. Политика устанавливает основные цели развития общества, социальные стандарты уровня жизни, гражданско-правовые нормы и правила государственного регулирования социального развития в целом. Влияя на воспроизводство человека, демографические, экономические и политические факторы определяют социальную ответственность государства за жизнь и безопасность своих граждан, соответствие их индивидуального уровня жизни установленным социальным стандартам [2, с. 160$]$.

Термин «социальная защита» был впервые использован в Законе о социальной защите США в 1935 г. [3, с. 35], и вскоре данный термин стал широко применяться во многих странах мира и Международной организацией труда (МОТ), так как просто и доходчиво выражал сущность проблемы по организации национальных программ и систем помощи престарелым и нетрудоспособным. В дальнейшем рамки этой дефиниции значительно расширились при разработке и принятии конвенций и рекомендаций МОТ, Всемирной организации здравоохранения (ВОЗ), Международной ассоциации социального обеспечения (MACO) по социальному страхованию и социальной помощи, гарантированию минимальных доходов работающим при наступлении нетрудоспособности, а также в области условий и охраны труда, заработной платы [4, с. 36].

Социальное обеспечение включает все пособия, в денежной и натуральной форме, которые предоставляют защиту, в том числе от:

- потери заработка (или получения недостаточного дохода) вследствие временной нетрудоспособности, инвалидности, беременности и родов, производственной травмы, безработицы, старости или смерти члена семьи;

- недоступности медицинских услуг из-за ограниченности доступа или их излишне высокой стоимости;

- недостаточной семейной поддержки, особенно детям и взрослым иждивенцам;

- бедности и социальной изоляции [3, с. 13].

В рекомендациях МОТ есть два основных (функциональных) направления развития социальной защиты: «обеспечение дохода» и «доступ к медицинскому обслуживанию», соответствующие определения которых даны в Рекомендации МOT 1944 года об обеспечении дохода (№ 67) и Рекомендации МОТ 1944 года о медицинском обслуживании (№ 69), где эти направления названы «главными элементами социального обеспечения».[5, с. 54] Данные рекомендации предусматривают, во-первых, что «системы обеспечения дохода должны уменьшать нуждаемость и предотвращать бедность путем восстановления до приемлемых размеров дохода, утраченного по причине нетрудоспособности (включая старость) или в связи с неспособностью получить оплачиваемую работу, или по причине смерти кормильца» (№ 67, Руководящие принципы, п. 1). Во-вторых, «служба медицинского обслуживания должна обеспечить каждому лицу медицинский уход со стороны лиц медицинской и смежных с нею профессий», и "медицинское обслуживание должно распространяться на всех членов коллектива» (пп. 1 и 8).

\section{Baikal Research Journal}

электронный научный журнал Байкальского государственного университета 
Предоставление доступа к социальному обеспечению в его основном значении является обязанностью общества, которое, как правило, решает эту задачу через государственные учреждения, финансируемые либо за счет уплаты взносов, либо из налогов. Однако социальное обеспечение может предоставляться (и предоставляется) и частными организациями (страховыми компаниями, обществами взаимопомощи и самопомощи), которые могут частично брать на себя функции, обычно присущие системе социального обеспечения. В числе прочего они предлагают профессиональные пенсионные программы, которые могут стать существенным дополнением к государственным системам социального обеспечения. Права на социальное обеспечение предоставляются на определенных условиях. Это либо определенный стаж уплаты социальных взносов (в системах, основанных на уплате взносов, чаще всего работающих на принципах социального страхования), либо так называемые «дополнительные выгоды для жителей страны, когда пособия предоставляются всем жителям страны, соответствующим определенным критериям (не обусловленные уплатой взносов системы). Иногда права на получение пособий дают возраст, состояние здоровья, рынок труда, доходы или другие параметры, определяющие социальный или экономический статус и (или) следование определенному типу поведения.

Особым случаем является основанная на проверке доходов социальная помощь, предусмотренная положениями Рекомендации № 67 об обеспечении дохода. Социальная помощь отличается от иных форм социальной поддержки следующими особенностями:

- пособия предоставляются получателям без каких-либо встречных обязательств с их стороны;

- социальная помощь не основана на уплате взносов, обычно финансируется из налогов или иных государственных доходов.

Единственным условием во всеобщих системах, предоставляющих пособия всем жителям страны, является проживание на ее территории. Подобные системы вводились в основном для предоставления гарантированного доступа к медицинскому обслуживанию. Как правило, они финансируются из налогов, однако могут требовать софинансирования от потребителей медицинских услуг, иногда за исключением самых малоимущих (обычно получающих ваучеры).

В современных системах социальной защиты населения существуют системы для отдельных категорий населения. Самыми распространенными из них являются системы перераспределения доходов в пользу пожилых граждан старше определенного возраста и детей младше определенного возраста. Некоторые системы предназначены для семей определенного типа (например, неполных семей) или профессиональных групп (например, работников сельского хозяйства). Эти системы также можно отнести к разряду всеобщих, если они охватывают всех лиц, относящихся к определенной группе или имеющих определенный уровень дохода (как в системах социальной помощи). Они могут требовать выполнения и других условий, например, определенных заданий. Большинство систем для определенных категорий граждан финансируется из налогов.

В настоящее время шесть из 31 конвенции социального обеспечения по-прежнему отвечают требованиям современности (по мнению МОТ) [6, с. 178]:

- Конвенция 1952 года о минимальных нормах социального обеспечения (№ 102);

- Конвенция 1964 года о пособиях в случаях производственного травматизма (№ 121);

- Конвенция 1967 года о пособиях по инвалидности, по старости и по случаю потери кормильца (№ 128);

\section{Baikal Research Journal}


- Конвенция 1969 года о медицинской помощи и пособиях по болезни (№ 130);

- Конвенция 1988 года о содействии занятости и защите от безработицы (№ 168);

- Конвенция 2000 года об охране материнства (№ 183).

Кроме того, существует Конвенция 1962 года о равноправии в области социального обеспечения (№ 118), которая провозглашает равенство граждан страны, иностранцев и лиц без гражданства при охвате различными видами социального обеспечения, при предоставлении пособий за рубежом, а также соблюдение прав во время их приобретения. Конвенция 1982 года о сохранении прав в области социального обеспечения (№ 157) рассматривает этот вопрос более широко.

Социальная защита населения страны, по мнению специалистов МОТ, состоит из десяти элементов:

1. Защита на случай временной нетрудоспособности, которая включает медицинское обслуживание.

2. Защита на случай временной нетрудоспособности, которая включает поддержку дохода в форме денежных пособий на случай временной нетрудоспособности.

3. Защита на случай инвалидности, в том числе поддержка дохода, а также медицинское обслуживание, реабилитация и длительный уход - пособие по поддержке доходов в случае инвалидности.

4. Защита в старости, в том числе поддержка дохода и длительный уход пособие по поддержке доходов в старости.

5. Защита иждивенцев в случае смерти члена семьи (кормильца) - пособие по защите доходов.

6. Защита материнства, в том числе медицинское обслуживание и поддержка доходов в форме пособия по беременности и родам.

7. Поддержка «ответственности за воспитание детей», в том числе помощь детям в натуральной форме - «продовольствие, одежда, жилая площадь, отдых и помощь по дому», а также денежная поддержка в виде семейных пособий.

8. Защита от безработицы, в том числе поддержка доходов в форме пособий по безработице, а также другие меры на рынке труда, повышающие занятость пособия по поддержке доходов.

9. Защита в случае производственной травмы: медицинское обслуживание, реабилитация и поддержка доходов в форме пособия по временной нетрудоспособности, инвалидности или потере кормильца.

10. Общая защита от бедности и социальной изоляции посредством оказания социальной помощи всем жителям, не имеющим других источников достаточного дохода от трудовой деятельности и не охваченных (или недостаточно охваченных) видами социального обеспечения, описанными выше ${ }^{1}$.

Существуют еще как минимум три других международных классификации областей социального обеспечения, которые полностью укладываются в приведенное нами выше расширенное описание социального обеспечения.

Так, Европейская комиссия В своей Европейской системе интегрированной статистики по социальной защите (ESSPROS) Статистическое бюро EUROSTAT выделяет восемь функций социальной защиты (European Commission, 2008): ceмья и дети; заболевание и охрана здоровья; потеря кормильца; инвалидность; старость; безработица; жилье; социальная изоляция, не подпадающая под другие разделы классификации.

\footnotetext{
${ }^{1}$ Социальное обеспечение в мире в 2010-2011 гг. Обеспечение охвата во время и после кризиса / Группа техн. поддержки по вопр. достойного труда и Бюро МОТ для стран Вост. Европы и Центр. Азии. М. : МОТ, 2011. С. 98.
}

\section{Baikal Research Journal}


Данная классификация включает две дополнительных функции, которые не рассматриваются явным образом в Конвенциях МОТ:

1. Обеспечение жильем, которое включает три пособия в натуральной форме:

- жилищную субсидию, которая определяется как основанный на проверке доходов трансферт, выделяемый государством съемщика жилья временно или на долгосрочной основе, чтобы помочь им выплачивать стоимость аренды;

- социальное жилье, предоставляемое на основе проверки доходов на некоммерческой основе (т. е. по цене аренды ниже рыночной) государством или частными некоммерческими организациями, владеющими дешевым или социальным жильем;

- основанная на проверке доходов государственная субсидия проживающим собственникам жилья для частичной помощи по оплате жилищных расходов: на практике это часто означает помощь в выплате ипотеки и (или) процентов по кредиту.

2. Защита на случай социальной изоляции, которая включает все прочие пособия, в основном - пособия социальной помощи, не покрывающие какие-либо конкретные риски или потребности, охваченные другими элементами защиты; она направлена на борьбу с "социальной изоляцией» или "риском социальной изоляции». В данном случае целевой группой являются малоимущие, мигранты, беженцы, лица, страдающие алкогольной или наркотической зависимостью, или жертвы преступного насилия.

Организация экономического сотрудничества и развития (ОЭСР) ОЭСР по примеру Еврокомиссии разработала для использования в своей базе данных SOCX (OECD, 2009a) следующую классификацию девяти направлений политики в области социального обеспечения: иждивенцы; ограниченные возможности; здоровье; старость; активные программы на рынке труда; семья; безработица; жилье; другие области социальной политики.

Главное отличие классификации ОЭСР от классификации ЕС состоит в том, что ОЭСР выделяет программы на рынке труда, не включенные в основную базу данных ESSPROS и меры непрямой помощи, такие как надбавки к заработной плате, в отдельную область социальной политики: активные программы на рынке труда (функция безработица в ESSPROS подразумевает только пособия по безработице и подобные им системы поддержки доходов, выходные пособия и аналогичные выплаты, предпенсионные пособия и другие пенсии, назначаемые в случае досрочного выхода на пенсию из-за условий на рынке труда, и возмещение расходов на обучение и другие способы повышения квалификации безработных).

Рассматривая развитие взглядов на роль социальной защиты в жизни общества, нельзя не отметить получившее в последнее время широкое развитие подход «минимального уровня социальной защиты» [7, с. 52]. Термин «социальный минимум» или «минимальный уровень социальной защиты» используется для обозначения основных прав, услуг и учреждений, которые должны быть доступны жителю глобального мира. Термин «социальный минимум» во многом соответствует существующему понятию «основные обязательства», которое означает гарантированное соблюдение по крайней мере минимального уровня прав, включенных в соглашения о правах человека. Организация Объединенных Наций (UN, 2009a) предполагает, что минимальный уровень социальной защиты должен включать два основных элемента, которые помогают реализовать соответствующие права человека ${ }^{2}$ :

- услуги: географический и финансовый доступ к основным услугам - водоснабжению и канализации, здравоохранению и образованию;

\footnotetext{
${ }^{2}$ Организация объединенных наций [Электронный ресурс] : офиц. сайт. URL: http://www.un.org.
}

\section{Baikal Research Journal}

электронный научный журнал Байкальского государственного университета 
- выплаты: базовый набор социальных выплат в денежной и натуральной форме в качестве помощи малоимущим и уязвимым лицам для обеспечения минимальной защиты их доходов и доступа к основным услугам, включая здравоохранение.

MOT в рамках своей кампании по расширению охвата социальным обеспечением выступает за усиление роли социальных трансфертов в базовой социальной защите, т. е. в минимальном социальном обеспечении. Имеется в виду минимальный базовый набор жизненно важных социальных гарантий, предоставляемых в денежной и натуральной форме, которые могут обеспечить всем нуждающимся минимальный уровень защиты доходов и доступ к медицинскому обслуживанию.

Целью базового набора гарантий является создание во всех без исключения странах условий, при которых:

- все жители настолько финансово защищены, что могут позволить себе воспользоваться доступной национальной системой базовых медицинских услуг, а государство берет на себя ответственность за обеспечение необходимого, как правило, диверсифицированного финансирования и оказания услуг;

- все дети получают гарантированную финансовую поддержку, по крайней мере на уровне национального прожиточного минимума, в форме детских пособий, которые должны обеспечить им доступ к полноценному питанию, образованию и уходу;

- всем гражданам экономически активного возраста, которые не могут заработать достаточно средств на рынке труда, должен быть обеспечен минимальный уровень гарантированного наряду с гарантиями занятости и другими мерами, касающимися рынка труда;

- все граждане пожилого возраста и лица с ограниченными возможностями имеют гарантированный доход, по меньшей мере на уровне национального прожиточного минимума, в форме пенсий по старости и инвалидности. Ни при каких условиях уровень пособий не должен быть ниже минимума, обеспечивающего доступ к базовой потребительской корзине товаров и услуг.

Исходя из этого можно оценить уровень охвата населения страны минимальным уровнем социальной защиты. Лица, получающие гарантированную защиту в рамках десяти пунктов расширенного определения МОТ и пособия не ниже минимального уровня, указанного в Конвенции 1952 года (№ 102) о минимальных нормах социального обеспечения, считаются обеспеченными всесторонней социальной защитой. Лица, которым обеспечивается защита доходов лишь на базовом уровне (гарантированный доход на уровне прожиточного минимума) на всех этапах жизненного цикла и которым обеспечен доступ к базовым услугам здравоохранения, считаются обеспеченными базовой социальной защитой (минимальным уровнем социального обеспечения). Лица, получающие защиту по одному из десяти направлений (не все они обеспечивают полноценную или базовую защиту), попадают под частичный базовый или частичный всесторонний охват.

Главной целью всех норм является обеспечение всесторонней защиты как можно большему числу людей, а целью на среднесрочную перспективу - обеспечение всем по меньшей мере минимального уровня защиты $[8$, с. 98].

В настоящее время международные организации, занятые вопросами развития национальных систем социальной защиты населения отмечают появление новых угроз и вызовов ${ }^{3}$. В первую очередь, они связаны с современным состоянием климата и ограниченностью природных ресурсов. Они характеризуются неопре-

${ }^{3}$ Справочник по расширению охвату работников мигрантов социальным обеспечением [Электронный pecypc]. URL: www.issa.int.

\section{Baikal Research Journal}


деленностью относительно своего масштаба и природы. Многие из них взаимосвязанны, сложны и труднопрогнозируемы. Они могут включать в себя:

1. Увеличение числа экстремальных климатических явлений, приводящих к экономической и социальной дезорганизации и вынужденному перемещению населения [9, с. 172].

2. Ухудшение состояния окружающей среды и рост нагрузки на основные природные ресурсы, что вызывает повышение цен и социальные конфликты.

3. Замедление темпов экономического роста как следствие роста народонаселения, увеличения потребления на душу населения и ограниченности природных ресурсов.

4. Снижение трудовой доли ВВП, находящее свое отражение в падении реальной заработной платы и усилении неравенства, касающегося статуса занятости.

5. Рост смертности и заболеваемости с ухудшением состояния здоровья населения во многих регионах мира.

Эти последствия окажут прямое влияние на требования, предъявляемые к системам социального обеспечения, и на ресурсы, которыми они располагают. К ним относятся:

1. Необходимость реагировать на экстремальные климатические явления (такие как наводнения, эрозия береговой линии и оползни).

2. Последствия увеличения миграции и вынужденного перемещения населения, а также нестабильная ситуация на рынках труда.

3. Повышение вероятности социальных конфликтов.

4. Замедление темпов экономического роста, влияющее на ресурсную базу системы социального обеспечения и на дополнительные программы социальной помощи для населения (например, программы работодателей) [10, с. 20].

5. Непосредственное воздействие на стоимость и размер доходов, получаемых за счет резервов фондов социального обеспечения.

6. Сокращение продолжительности жизни определенных групп населения, рост показателей заболеваемости и возникновение новых вызовов перед системами здравоохранения в ряде регионов.

Несмотря на существенный характер будущих вызовов, уже принимается целый ряд мер в области политики и администрирования, нацеленные на решение определенных проблем, вызванных изменениями климата и дефицитом природных ресурсов. Как подчеркивается специалистами МОТ, социальное обеспечение, учитывающее климатические факторы, уже стало реальностью в ряде стран. Их опыт может стать примером для будущих действий; он может развиваться с учетом изменений во внешней среде.

В любой стране все системы и институты социального обеспечения взаимосвязаны и имеют взаимодополняющие задачи, функции и финансирование, образуя единую национальную систему социального обеспечения [11]. Для повышения эффективности (к чему МОТ неизменно призывает своих участников) важно, чтобы отдельные части системы работали согласованно. Для облегчения координации и планирования приходно-расходные операции отдельных программ должны быть сведены в единый национальный бюджет социального обеспечения. Это поможет лучше планировать будущие расходы и финансирование программ, составляющих систему социального обеспечения.

Подходы необходимо согласовывать с другими заинтересованными сторонами, что обеспечит слаженность принимаемых мер и эффективное использование ресурсов. При этом учреждения социального обеспечения могут и впредь играть значимую роль в том, как общество борется с одной из ключевых проблем, стоящих перед человечеством в этом столетии.

\section{Baikal Research Journal}

электронный научный журнал Байкальского государственного университета 


\section{Список использованной литературы}

1. Метелева Е. Р. Определение ключевых терминов в социальной сфере / Е. Р. Метелева // Известия Иркутской государственной экономической академии. - 2016. - Т. 26, № 1. - C. 90-98. - DOI: 10.17150/1993-3541.2016.26(1).90-98.

2. Янова С. Ю. Социальное страхование в системе социальной защиты населения (организация и финансовый механизм) : дис. ... д-ра экон. наук : 08.00.10 / С. Ю. Янова. СПб., 2001. - 400 с.

3. Вознюк Г. А. Социальное страхование работников промышленного предприятия как фактор повышения качества жизни: на примере ОАО «Нижнекамскнефтехим» : дис. ... канд. социол. наук : 22.00.03 / Г. А. Вознюк. - Казань, 2009. - 203 с.

4. Роик В. Д. Основы социального страхования: организация, экономика и право : учебник / В. Д. Роик. - М. : Изд-во Рос. акад. гос. службы, 2007. - 456 с.

5. Мартынова Т. Н. Современное состояние и перспективы развития системы социальной защиты семьи / Т. Н. Мартынова. - Кемерово : Кемер. гос. ун-т, 2009. - 83 с.

6. Лушникова М. В. Курс права социального обеспечения / М. В. Лушникова, А. М. Лушников. - М. : Юстицинформ, 2009. - 656 с.

7. Лебедзевич Я. В. Система социальной защиты: эволюция и взаимосвязь категорий / Я. В. Лебедзевич // Финансы и кредит. - 2014. - № 23. - С. 48-55.

8. Кротов М. В. Выступления полномочного представителя Президента РФ в Конституционном Суде Российской Федерации : сборник / М. В. Кротов. - М. : Проспект, 2013. $640 \mathrm{c}$.

9. Василишина Н. В. Негативные последствия экономического кризиса и проблемы деятельности Международной организации труда / Н. В. Василишина // Известия Иркутской государственной экономической академии. - 2011. — № 6 (80). — С. 171-174.

10. Ржаненков А. Н. Социальная защита населения: достижения года минувшего и перспективы совершенствования / А. Н. Ржаненков // Социальное обслуживание. 2013. - № 3. - С. 9-22.

11. Инкижинова С. А. Социальная защита как фактор регулирования качества жизни населения / С. А. Инкижинова // Известия Иркутской государственной экономической академии (Байкальский государственный университет экономики и права). - 2011. № 6. - Режим доступа: http://brj-bguep.ru/reader/article.aspx?id=14072.

\section{References}

1. Meteleva E. R. Defining the key terms of social welfare. Izvestiya Irkutskoi gosudarstvennoi ekonomicheskoi akademii = Bulletin of Irkutsk State Economics Academy, 2016, vol. 26, no. 1, pp. 90-98. DOI: 10.17150/1993-3541.2016.26(1).90-98. (In Russian).

2. Yanova S. Yu. Sotsial'noe strakhovanie v sisteme sotsial'noi zashchity naseleniya (organizatsiya $i$ finansovyi mekhanizm). Dokt. Diss. [Social insurance in public welfare system (organization and financial mechanism) Doct. Diss.]. Saint Petersburg, 2001. 400 p.

3. Voznyuk G. A. Sotsial'noe strakhovanie rabotnikov promyshlennogo predpriyatiya kak faktor povysheniya kachestva zhizni: na primere OAO «Nizhnekamskneftekhim». Kand. Diss. [Social insurance of industrial company's workers as a factor of improving the quality of life: through the example of OSJC «Nizhnekamskneftekhim» Cand. Diss.]. Kazan, 2009. 203 p.

4. Roik V. D. Osnovy sotsial'nogo strakhovaniya: organizatsiya, ekonomika i pravo [Basics of Social Insurance: Organization, Economy and Law]. Moscow, Russian Presidential Academy of National Economy and Public Administration Publ., 2007. 456 p.

5. Martynova T. N. Sovremennoe sostoyanie i perspektivy razvitiya sistemy sotsial'noi zashchity sem' $i$ [Current state and development prospects for system of family social protection]. Kemerovo State University Publ., 2009. 83 p.

6. Lushnikova M. V., Lushnikov A. M. Kurs prava sotsial'nogo obespecheniya [Course of Public Welfare Law]. Moscow, Yustitsinform Publ., 2009. 656 p.

7. Lebedzevich Ya. V. Social protection system: evolution and interrelationship of categories. Finansy $i$ kredit $=$ Finance and Credit, 2014, no. 23, pp. 48-55. (In Russian).

8. Krotov M. V. Vystupleniya polnomochnogo predstavitelya Prezidenta RF $v$ Konstitutsionnom Sude Rossiiskoi Federatsii [Public speaking of Plenipotentiary of the President in the Constitutional Court of the Russian Federation]. Moscow, Prospekt Publ., 2013. 640 p.

\section{Baikal Research Journal}


9. Vasilishina N. V. Adverse effects of economic crisis and problems of international labour organization activity. Izvestiya Baykal'skogo gosudarstvennogo universiteta = Bulletin of Baikal State University, 2011, no. 6 (80), pp. 171-174. (In Russian).

10. Rzhanenkov A. N. Welfare: achievements of the past year and improvement prospects. Sotsialnoe obsluzhivanie $=$ Social Service, 2013, no. 3, pp. 9-22. (In Russian).

11. Inkizhinova S. A. Social protection as a factor of regulating the life quality. Izvestiya Irkutskoi gosudarstvennoi ekonomicheskoi akademii (Baykalskii gosudarstvennyi universitet ekonomiki i prava) = Bulletin of Irkutsk State Economics Academy (Baikal State University of Economics and Law), 2011, no. 6. Available at: http://brj-bguep.ru/reader/article.aspx?id=14072. (In Russian).

\section{Информация об авторе}

Агеева Евгения Валерьевна - кандидат экономических наук, доцент, кафедра страхования и управления рисками, Байкальский государственный университет, 664003, г. Иркутск, ул. Ленина, 11, e-mail: ageeva-ev@bgu.ru.

\section{Author}

Evgeniya V. Ageeva- PhD in Economics, Associate Professor, Chair of Insurance and Risk Management, Baikal State University, 11 Lenin St., 664003, Irkutsk, Russian Federation; e-mail: ageeva-ev@bgu.ru.

\section{Библиографическое описание статьи}

Агеева Е. В. Подходы к роли социальной защиты населения в жизни общества и современные вызовы, стоящие перед ней / Е. В. Агеева // Baikal Research Journal. — 2017. — T. 8, № 2. — DOI: 10.17150/2411-6262.2017.8(2).33.

\section{Reference to article}

Ageeva E. V. Approaches to role of social protection for the public in society's life and mod-ern challenges facing it. Baikal Research Journal, 2017, vol. 8, no. 2. DOI: 10.17150/2411-6262.2017.8(2).33. (In Russian).

\section{Baikal Research Journal}

